\title{
Studies on the Influence of Active Substances from Medicinal Plants on Some Pathogen of Wheat Crops
}

\author{
Daniela TRIFAN ${ }^{1 *}$, Emanuela LUNGU ${ }^{1}$ \\ ${ }^{1}$ Agricultural Research and Development Station of Braila, Romania, \\ Km. 9, Sos. Vizirului, cod. 810008, Braila, Romania \\ *Corresponding author: dana.trifan@yahoo.com \\ Bulletin USAMV series Agriculture 72(2)/2015 \\ Print ISSN 1843-5246; Electronic ISSN 1843-5386 \\ DOI 10.15835/buasvmcn-agr: 11378
}

\begin{abstract}
Plant extracts used to control of the phytopathogens have been obtained mainly from Coriandrum sativum, Artemisia absinthium, Capsicum annuum, Ocimum basilicum, Althaea officinalis, Thymus vulgaris, Lycopersicon esculentum, Calendula officinalis, Mentha piperita, Tagetes patula. Rosmarinus officinalis, Achillea millefolium, Urtica dioica, in different doses of extracts. Inseminations were performed with the wheat pathogens cultured in the laboratory and we studied the influence of plant extracts on the development of microorganisms. Measurements were performed on cultures of microorganisms and microscopic counts accurate.
\end{abstract}

Keywords: pesticide, medicinal plants, wheat diseases.

\section{INTRODUCTION}

A series of spontaneous plants have the ability to defend themselves from pests and diseases due to the content in antibiotic substances and insecticides. Therefore, many wild plants used in herbal medicine and in the preparation of antiseptic soaps. The idea of using herbs as a pesticide plant is not new; it is used in mixed cultures long time ago. The extraction of active substances from medicinal plants also is not new, but studies testing the effect they have these antibiotic substances extracted from medicinal plants grown on plant diseases are laborious and takes more time to approval of a biological pesticide. The phytopathogenic attack on the wheat crop is one of the reasons due to which wheat production not exploit the full potential (Arsene, 2013). In Romania, there is an increasingly frequent largest wheat powdery mildew, caused by the pathogen Bumeria graminis $f s p$. tritici, which significantly reduces photosynthesis in the leaves, the leaves assimilation index decreases, affecting productivity elements and greatly decreasing production of wheat (Paraschiv, 2014).

\section{AIMS AND OBJECTIVES}

Minimizing the impact of pesticides on the environment can be made only through the development of biological control of plant diseases and pests through the use of natural antimicrobial substances. The current study suggests the use of medicinal plant extracts for some diseases of wheat. The aim of the research was to identify the most effective herbal extracts of Blumeria graminis and to observe the changes that they suffer under the traits influence. The objectives were: to perform extracts of medicinal plants from their own culture, conducted under experimental center Chiscani, crops that have not been chemically treated, to isolate the fungus and development of culture in vitro, to make observation of growing $B$. graminis making smears with measuring microscope, to trait with extracts of medicinal plants and observing how each extract acts (alone or mixed) on the colonies. 


\section{MATERIALS AND METHODS}

The study was conducted in laboratory Agricultural Research and Development Station of Braila through the following steps: withdrawal of leaves and wheat ears attacked by B. graminis, achieving a culture medium with wheat and corn starch, placing them in Petri dishes and sterilizing, establishing Blumeria colonies on culture media and ensure their development thermostatically at $25^{\circ} \mathrm{C}$, cultivation of medicinal plants needed in harvesting phenophases that ensured maximum content of active antibiotic substances, making extracts of 13 species of medicinal plants, using fresh parts of plants, distilled water in the ratio of $1: 100$, treating Blumeria cultures with different types of extracts with microscopic observation of effects. We have experienced these herbal extracts: Coriandrum sativum, Artemisia absinthium, Capsicum annuum, Ocimum basilicum, Althaea officinalis, Thymus vulgaris, Lycopersicon esculentum, Calendula officinalis, Mentha piperita, Tagetes patula, Rosmarinus officinalis, Achillea millefolium, Urtica dioica. After observing the effects on colonies, we elected six extract and were done nine mixtures, depending on the effects that they produced of anatomic level, and the results were compared to an untreated control (V10):

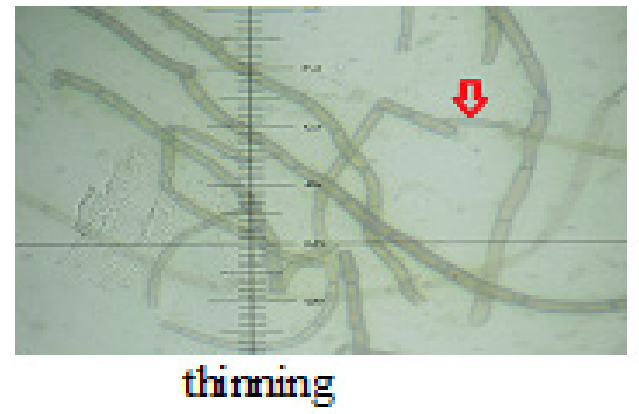

\begin{tabular}{cccc}
\hline $\begin{array}{c}\text { Extracts } \\
\text { combination }\end{array}$ & $\begin{array}{c}\text { Urtica } \\
\text { dioica }\end{array}$ & $\begin{array}{c}\text { Capsicum } \\
\text { annuum }\end{array}$ & Tagetes patula \\
\hline $\begin{array}{c}\text { Arthemisia } \\
\text { absinthium }\end{array}$ & V1 & V2 & V3 \\
\hline $\begin{array}{c}\text { Ocimum } \\
\text { basilicum }\end{array}$ & V4 & V5 & V6 \\
\hline $\begin{array}{c}\text { Achilea } \\
\text { millefolium }\end{array}$ & V7 & V8 & V9 \\
\hline
\end{tabular}

\section{RESULTS AND DISCUSSION}

After inoculation of $B$. graminis on culture medium was observed while developing colonies or germinal tube formation of primary, secondary, and training other colonies of haustors so, after 7 days after inoculation, were able to make the first counts and treatment with plant extracts. Among the effects observed, especially thinning of haustors found that manifested to treatment with Artemisia absinthium, Ocimum basilicum and Achilea millefolium, and breaking of haustors observed in treatment with Urtica dioica, Capsicum annuum and Tagetes patula (Fig. 1) that may explain finally reducing the number of colonies of B. graminis.

All variants have reduced the number of colonies of B. graminis, at least $10 \%$ of the original

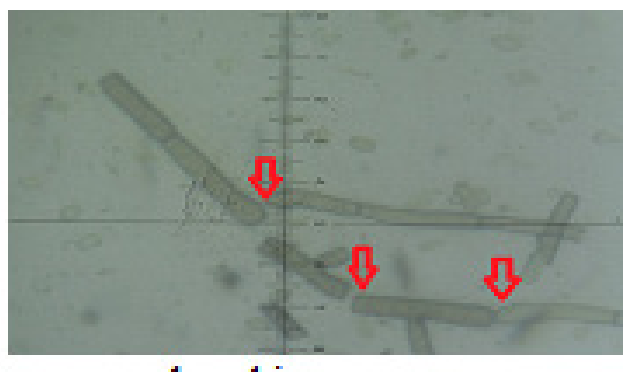

breaking

Fig. 1. Effects of medicinal plants extracts on B. graminis colonies
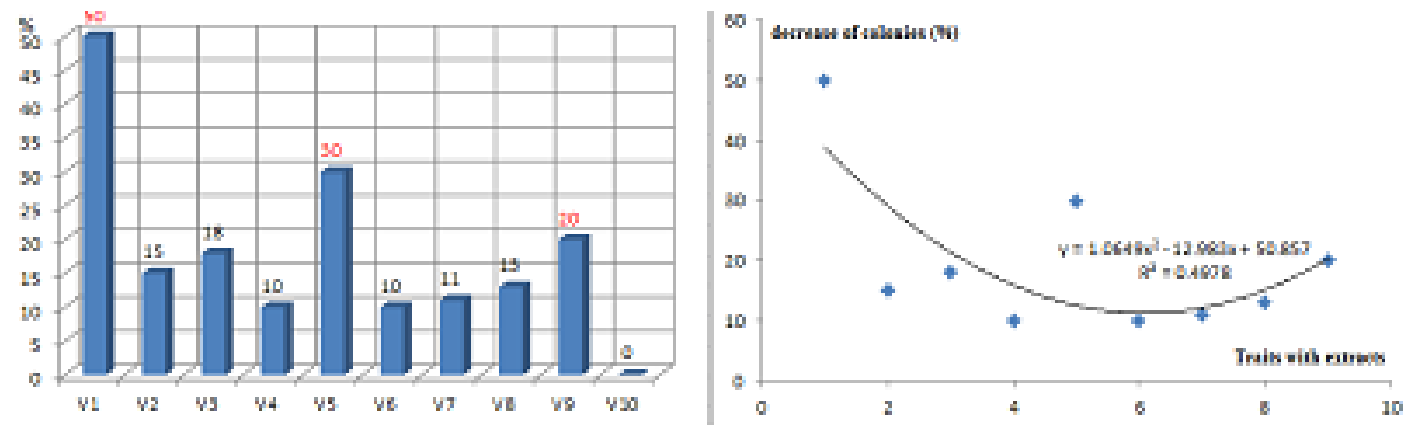

Fig. 2. Decrease number of B. graminis colonies and correlation graph 
number, but the best result was obtained V1 version, which contributed to a $50 \%$ reduction in the number of colonies, followed in descending order V5 variants (30\%) and V9 (20\%) (Fig. $2)$, seeing a positive correlation between the treatments performed and the effect on reducing colonies B. graminis.

\section{CONCLUSION}

The experiment proved that some herbal extracts may have antibiotic effects, so can help to treat diseases of crop plants. The most effective combination of extracts were between Urtica dioica $x$ Artemisia absintium, Capsicum annuum $x$ Ocimum basilicum and Tagetes patula $x$
Achillea millefolium, which will be used on these experiences in vegetation pots and in the field.

\section{REFERENCES}

1. Arsene C.I., Andreea-Mihaela Balau, E. Ulea (2013). Some wheat varieties behavior regarding the attack of main pathogens under climatic conditions from central area of Moldavia, Romania, Cercetări Agronomice în Moldova Vol. XLVI , No. 3 (155) / 2013

2. Stevenson Phil (2014). Using pesticidal plants for crop protection http://www.kew.org/discover/blogs/usingpesticidal-plants-crop-protection

3. Paraschivu Mirela, Cotuna Otilia, Partal Elena (2014). Assessment of blumeria graminis f.sp. tritici attack on different Romanian winter wheat varieties, Research Journal of Agricultural Science, 46 (2) 